\title{
Canopy wetness patterns in a Mediterranean deciduous stand
}

Pilar Llorens (1), Francisco Domingo (2), Pablo Garcia-Estringana (1), and Francesc Gallart (1)

(1) Institute of Environmental Assessment and Water Research (IDÆA)-CSIC, Barcelona, Spain (pilar.llorens@idaea.csic.es),

(2) Arid Zones Research Station (EEZA), CSIC. Almería, Spain.

The separation of rainfall events by intervals sufficiently long for the canopy and stems to dry completely is one of the assumptions of rainfall interception analytical models (i.e. Gash 1979 and derivative models). This approximation assumes that canopy storage compartments are empty at the beginning of each storm and, as a consequence, each rainfall event has a closed water balance. In practice, a fixed number of hours is used to separate rain events, either for data treatment or modelling.

The evaluation of whether this practical assumption is appropriate for stands with seasonal changes, both in canopy and rainfall characteristics, is the main objective of the present work.

Canopy wetness duration was monitored during the leafed and leafless periods in a downy oak stand (Quercus pubescens Willd.) located in the Vallcebre research catchments $\left(42^{\circ} 12^{\prime} \mathrm{N}, 1^{\circ} 49^{\prime} \mathrm{E}\right)$. The canopy wetness duration measurements were made at 10 different heights within the canopy by means of electrical resistance sensors. Precipitation was registered in a nearby clearing and net radiation, air temperature, vapour pressure deficit (VPD), wind speed and direction above the canopy. This instrumentation was complemented with meteorological measurements at two heights, below and within de canopy.

The results indicate differences in wetness duration between the leafed and the leafless periods, and for each period between daytime and night-time rain events. The sensors remained long time wet during nights in leafed periods; on the contrary, it dried rapidly during days in leafless periods. Moreover, a stratification of the wetness profile was observed, with longer wetness durations in the low canopy levels and shortest ones at the top of the canopy, both in leafed and in leafless periods. Stratification can be linked to the meteorological conditions at each height, i.e. lower VPD and higher wind speeds at the top of the canopy along with the contrary conditions at the bottom. These results suggest that the assumption of using a fixed number of hours to separate rain events is not suitable for stands with seasonal changes. 